\title{
Investigational drugs for the treatment of AD: what can we learn from negative trials?
}

\author{
Sandra A Jacobson and Marwan N Sabbagh*
}

\begin{abstract}
Given the level of interest and activity in the race to find a treatment for Alzheimer's disease, it is expected that a reasonably safe and effective drug will be identified within the next decade. It may be worthwhile to pause periodically during the course of this race to take stock of what we have learned. Over the past few years, a number of trials have been conducted with promising new compounds (including some with novel mechanisms of action) that failed to meet primary endpoints and so were discontinued from clinical development. This article reviews a set of molecules with a range of mechanisms that have been trialed but with negative results. This article also examines the reasons for the negative findings and summarizes some of what we have learned from these experiences.
\end{abstract}

\section{Introduction}

In the two decades since the amyloid hypothesis was first proposed [1], a great deal of evidence has accrued in support of this mechanism in the pathogenesis of Alzheimer's disease (AD), mostly from preclinical studies of transgenic mice, autosomal dominant presenilin cases, and in vitro data supporting the neurotoxic effects of amyloid-beta $(A \beta)$. The theoretical promise of this model, however, has yet to be realized in the world of $\mathrm{AD}$ therapeutics. Robust treatments still seem elusive, even with an identified therapeutic target. Others have addressed the question of why this may be the case [2,3], and this review builds on that literature.

The process of drug development, from preclinical investigation through phase III study, is shown in Figure 1. Considering each phase separately helps to identify confounders that might be driving a type II error,

*Correspondence: marwan.sabbagh@bannerhealth.com

The Cleo Roberts Center for Clinical Research, Banner Sun Health Research Institute, 10515 W. Santa Fe Drive, Sun City, AZ 85351, USA if such an error exists in reference to new drug development for $\mathrm{AD}$.

Zahs and Ashe [2] reviewed mouse models of AD and made several observations in regard to translational research. These authors identified more than 300 reports of effective AD interventions based on these models. They noted, however, that none of the models is actually a complete replication of $\mathrm{AD}$. In fact, what the models do simulate is a presymptomatic phase of $\mathrm{AD}$, which might correspond to a time many years before a patient would present to a memory clinic or a subject would present to a clinical trial.

Becker and Greig [3] identified approximately 100 candidate drugs for $\mathrm{AD}$ with more than 40 different mechanisms of action, and 20 of those 100 drugs showed early promise through phase II studies. Table 1 of the authors' report shows a representative sample of 16 drugs trialed within the last decade, and most of them failed because of lack of efficacy in phase III study. Trials of these drugs are reviewed in more detail below.

\section{Immunotherapy: AN1792}

This was the first trial in humans of an active immunotherapy approach, in which A 442 was introduced as an antigen to stimulate antibody production against the entire $A \beta$ molecule, thus promoting clearance of amyloid. AN1792 is unique among the drugs discussed here because it ceased development because of safety concerns related to the occurrence of meningoencephalitis, a $\mathrm{T}$ cell-mediated inflammatory process that occurred in $6 \%$ of treated patients [4]. Responders were noted to have functional benefit after one to three doses, and antibodies were persistent for 5 years or more [5]. Overall, clinical benefits of the vaccine were modest, although survivor analysis favored treatment [5]. However, a post hoc study of subjects who were enrolled in the AN1792 study and who came to autopsy revealed that immunization with A 42 (AN1792) resulted in clearance of amyloid plaques in patients with $\mathrm{AD}$ but this clearance did not prevent progressive neurodegeneration [6]. Limited data from the trial suggested that immunotherapeutic interventions should be administered early in the course of the disease. Secondgeneration immunotherapy trials are now in progress. 


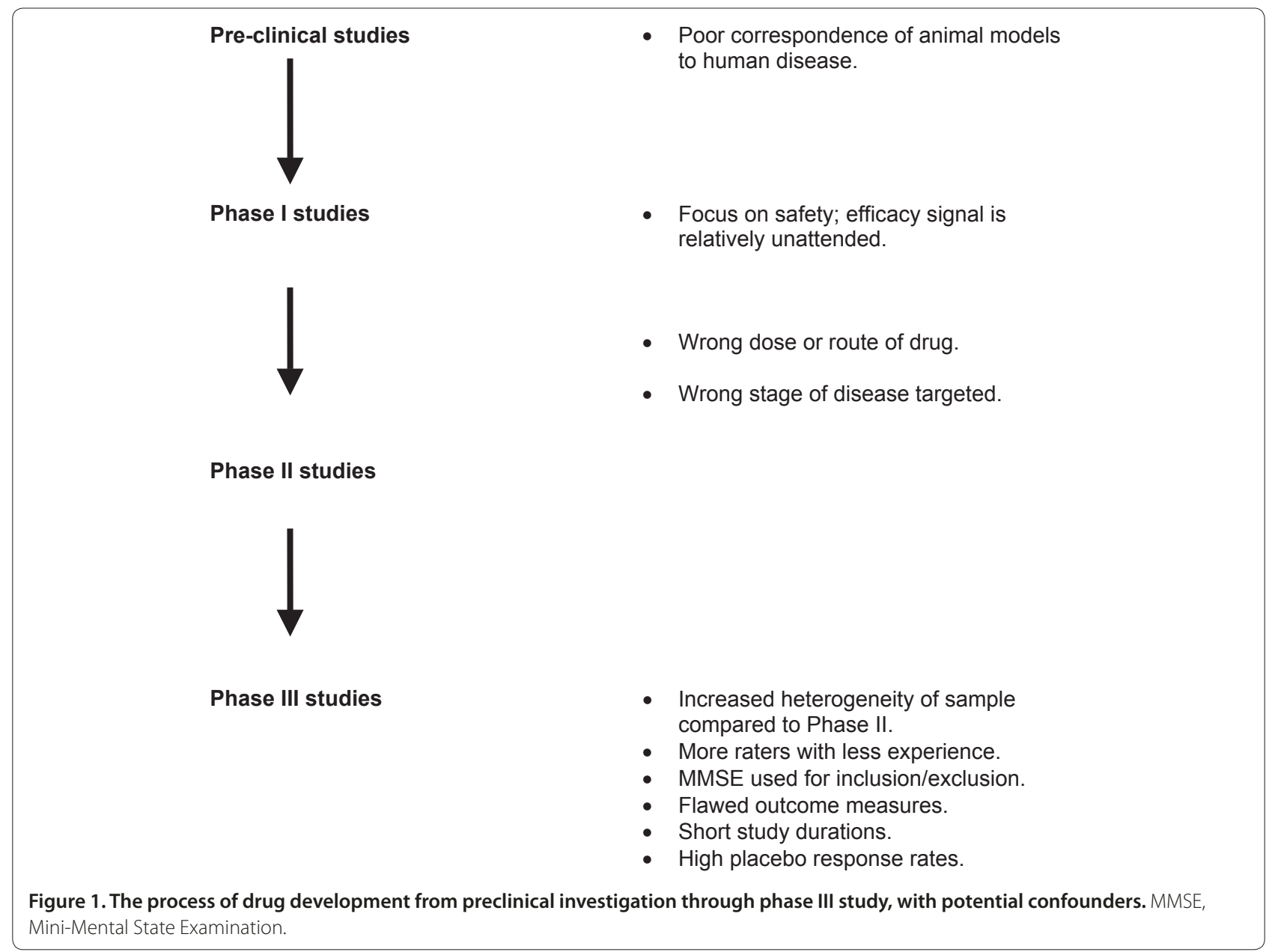

\section{Cholinergic drugs: phenserine and AZD3480}

Phenserine, a derivative of physostigmine, is a selective, noncompetitive acetylcholinesterase inhibitor that has additional effects on $\mathrm{A} \beta$ levels [7]. Phenserine interacts with the 5'- untranslated region of the APP (amyloid beta (A4) precursor protein) gene and reduces translation of APP mRNA into protein. Both the (-)- and the (+)-enantiomer of phenserine are equipotent in dosedependent and time-dependent negative regulation of APP mRNA translation, but (+)-phenserine (posiphen) is inactive as an acetylcholinesterase inhibitor and therefore may be administered at higher doses [8].

In a phase IIb study in 20 patients with mild $A D$, phenserine $30 \mathrm{mg} /$ day reduced cerebrospinal fluid (CSF) levels of $\mathrm{A} \beta$ as well as formation of amyloid plaques (as measured by retention of cortical Pittsburgh compound B-positron emission tomography, or PIB-PET) [9]. In a 6-month phase III trial in 384 patients with mild to moderate AD (Mini-Mental State Examination (MMSE) score of at least 10 and not more than 26), participants were randomly assigned to receive phenserine 10 or $15 \mathrm{mg}$ twice daily or placebo. At the completion of the trial, no significant differences were found between the phenserine and placebo groups on the Alzheimer's Disease Assessment Scale-cognitive subscale (ADAS-cog) or the Clinician's Interview-Based Impression of Change (CIBIC), the primary outcome measures. Two concurrent clinical trials were halted, and the data from these were merged for analysis, which also failed to demonstrate benefit of phenserine compared with placebo [10].

AZD3480 is an $\alpha 4 \beta 2$-selective nicotinic acetylcholine receptor (nAChR) agonist [11]. nAChRs in the central nervous system (CNS) are believed to be the primary cholinergic receptors lost in $\mathrm{AD}$, and agonists at these receptors were hypothesized to be viable symptomatic treatments. In the Sirocco Trial, subjects with mild to moderate $\mathrm{AD}(\mathrm{n}=659)$ were randomly assigned to receive one of three doses of AZD3480, a fixed dose of donepezil, or placebo for 12 weeks [12]. Although AZD3480 was comparable to placebo in terms of its overall safety and tolerability profile and was associated with fewer gastrointestinal-related adverse effects than donepezil, neither AZD3480 nor donepezil was significantly positive on the primary outcome measure 
(ADAS-cog) [12]. This is one of many trials in which improvement in the placebo group over time affected outcome. In addition, there was some concern that the study was too brief to detect a positive outcome, even for a symptomatic treatment. The minimum duration of a treatment trial is usually on the order of 24 weeks.

\section{Neuroprotection: Ginkgo biloba}

G. biloba is an herbal supplement that is widely believed to have efficacy in the prevention and treatment of agingassociated cognitive decline, including AD. Evidence suggests that this drug facilitates the clearance of $A \beta$ through regulation of the receptor for advanced glycation end-products and LRP-1 (low density lipoprotein receptorrelated protein 1) during brain ischemia [13]. Studies of the efficacy of this drug have had mixed results. An important and influential study was the National Institutes of Health-sponsored clinical trial at five academic medical centers between 2000 and 2008; in that study, an extract of G. biloba $120 \mathrm{mg}$ twice daily or placebo was administered to 3,069 elderly community-dwelling volunteers (2,587 with normal cognition and 482 with amnestic mild cognitive impairment, or MCI) [14]. Participants were evaluated every 6 months for the primary outcome measures of incident dementia and AD (determined by expert panel consensus). The results indicated no significant effect of G. biloba on the progression to AD (hazard ratio $(\mathrm{HR})=1.16,95 \%$ confidence interval $(\mathrm{CI}) 0.97$ to 1.39 ) or all-cause dementia ( $\mathrm{HR}=1.12,95 \% \mathrm{CI} 0.94$ to 1.33). A subset analysis in participants with amnestic MCI at baseline had similar results ( $\mathrm{HR}=1.13,95 \% \mathrm{CI}$ 0.85 to 1.50). Overall, a greater number of subjects treated with G. biloba developed dementia $(\mathrm{n}=277 ; 3.3$ per 100 person-years) in comparison with placebo $(\mathrm{n}=$ 246; 2.9 per 100 person-years), but the difference was not statistically significant. The findings of this study suggested no role for G. biloba in the prevention of $\mathrm{AD}$ or incident cognitive decline [14,15]. Meta-analyses of the studies of G. biloba in the treatment and prevention of dementia and cognitive decline show variable effects with an inconsistent signal $[16,17]$. The data in aggregate are contrary to the widely held view that Ginkgo prevents memory decline and, in fact, are contrary to earlier findings. In the larger community of outpatients, it is possible that Ginkgo self-administration is actually a marker for a healthy lifestyle, with high compliance by virtue of voluntary administration.

\section{Glutamatergic drugs: neramexane and SGS742}

Neramexane is an $N$-methyl $D$-aspartate (NMDA) receptor antagonist similar to memantine. These drugs are thought to reduce excitoxicity associated with excessive glutamatergic stimulation. In phase II trials, neramexane demonstrated reasonable safety and tolerability [18].
Presumably because of poor efficacy, the drug was not entered into phase III trials for AD; instead, the drug is under investigation for the treatment of tinnitus and pain. Given the mechanism of the drug, it would not be expected to influence disease progression in AD.

SGS742 is an orally active phosphoamino acid derivative that acts as a selective gamma-aminobutyric acid type $\mathrm{B}\left(\mathrm{GABA}_{\mathrm{B}}\right)$-receptor antagonist [19]. This drug was considered as a potential treatment for $\mathrm{AD}$ because activation of $\mathrm{GABA}_{\mathrm{B}}$ receptors had been found to inhibit memory/learning in animal models [19]. It was hypothesized that $\mathrm{GABA}_{\mathrm{B}}$ antagonists might reverse this effect by reducing glutamatergic excitotoxicity via indirect effects on NMDA receptors. Preclinical studies in rats, mice, and rhesus monkeys were positive. In the first phase II trial $(\mathrm{n}=110)$ in MCI, SGS742 was well tolerated at a dose of $600 \mathrm{mg}$ three times daily for 8 weeks [19]. Positive effects on attention, visual information processing, and working memory were demonstrated. In a phase IIb monotherapy trial $(n=280)$ in mild to moderate AD, SGS742 failed to meet the efficacy endpoints.

\section{Hormonal therapies: estrogen and leuprolide}

Hormone replacement therapy (HRT) has been proposed as a target for treatment and prevention in AD because of dampening effects on $A \beta$ demonstrated in preclinical studies [20,21]. A meta-analysis of 10 studies linked estrogen with a higher risk of dementia, a lower risk of dementia, and no association with dementia or AD [22]. A second meta-analysis noted a slight but inconsistently positive effect of estrogen on cognitive health [23]. A third meta-analysis concluded that, given the problems with study conduct and methodology plaguing studies of estrogen and cognition, the association between HRT and dementia risk was still unknown [24].

Results of the Women's Health Initiative Memory Study (WHIMS) indicate that HRT was not associated with a lower risk of dementia and in fact may be associated with an increased risk of dementia [25]. Subjects administered the combined HRT regimen of estrogen and progestin were twice as likely to develop dementia in comparison with those not treated with HRT. In a later WHIMS study, which looked at the use of estrogen monotherapy for women who previously had a hysterectomy, subjects on HRT had a $49 \%$ higher incidence of probable dementia during follow-up [26]. Both estrogen trials were terminated - estrogen and progestin in July 2002 and estrogen alone in February 2004 - because of adverse cardiovascular and stroke events and concern over increased breast cancer risk.

Trials of HRT in subjects with established AD have also been mostly negative. If HRT is to be pursued as prophylaxis or treatment of $\mathrm{AD}$, the investigation will likely focus on several unresolved issues, including the timing 
and duration of exposure required, and possible differences with the use of bioidentical or synthetic hormones.

As age is the leading risk factor for $\mathrm{AD}$, the question of whether the cause of $\mathrm{AD}$ is also age-related naturally arises. It is well established that estrogen and testosterone levels decline with age and that levels of folliclestimulating hormone (FSH) and luteinizing hormone (LH) rise because of reduced negative feedback to the HPA axis [27]. These gonadotropins stimulate not only gonadal steroid synthesis but also cell proliferation in the gonads, where A $\beta \mathrm{PP}$ and presenillins are highly expressed. LH receptors are present on neurons and are particularly abundant in the hippocampus. A preclinical study suggested that lowering LH levels might be beneficial in $\mathrm{AD}$ [28]. Increased LH levels have been found in brain in patients with AD $[29,30]$. Treatment of C57/Bl6 wild-type mice with leuprolide decreases $A \beta$ levels. Leuprolide is known to lower LH levels in humans and is marketed for the treatment of prostate cancer. In phase III trials, however, leuprolide failed because of lack of efficacy.

\section{Serotonin $\mathbf{5 H T}_{1 \mathrm{~A}}$ receptor antagonists: xaliproden}

Xaliproden was considered for the treatment of $\mathrm{AD}$ because of its nerve growth factor-like effects and its antagonism of the serotonin $1 \mathrm{~A}\left(5-\mathrm{HT}_{1 \mathrm{~A}}\right)$ receptor [31]. Consideration of $5-\mathrm{HT}_{1 \mathrm{~A}}$ antagonists for $\mathrm{AD}$ was based on preclinical data indicating that they facilitated glutamatergic and cholinergic neurotransmission [31] and that inhibition of the $5-\mathrm{HT}_{1 \mathrm{~A}}$ receptor resulted in the enhancement of cognitive abilities [31]. Two large phase III, 18-month clinical trials of xaliproden monotherapy $(\mathrm{n}=1,306)$ and adjunctive therapy $(\mathrm{n}=1,455)$ in patients with mild to moderate AD (MMSE score of 16 to 26) were completed in 2007 [32]. Lack of efficacy in both trials resulted in the cancellation of the xaliproden development program for AD in September 2007.

\section{Gamma secretase modulator: tarenflurbil}

Tarenflurbil, the R-enantiomer of the nonsteroidal antiinflammatory drug flurbiprofen, was the first gammasecretase modulator to reach the final stage of clinical development. Results of a phase II trial in 210 patients studied for 18 months did not meet the primary endpoint, but a post hoc analysis of subjects with mild AD (MMSE score of 20 to 26) found beneficial effects of tarenflurbil at a dose of $800 \mathrm{mg}$ twice daily in terms of measures of daily activities and global function [33].

The 18-month phase III trial $(n=1,600)$, conducted at 133 sites in the US, examined the effect of tarenflurbil $800 \mathrm{mg}$ twice daily in patients with mild AD (mean MMSE score of 23, range of 20 to 26), $81 \%$ of whom were receiving a stable dose of an acetylcholinesterase inhibitor, memantine, or a combination of these drugs [34]. The primary outcome measures were the ADAS-cog and ADAS activities of daily living (ADAS-ADL) scale, assessed every 3 months. There was no significant difference between the tarenflurbil and placebo groups; at the end of the study, both groups had declined by mean values of 7 points on the ADAS-cog and 10 points on the ADAS-ADL. With this magnitude of decline over 18 months, an efficacy signal should have been detectable. It is possible, as some have speculated, that tarenflurbil given orally did not adequately penetrate the CNS. It is also possible that gamma secretase modulation is best initiated before any plaque deposition has occurred (for example, in patients at risk of AD) and therefore would exert minimal effects with significant amyloid burden as is common in symptomatic AD.

\section{Statin drugs}

Elevated midlife cholesterol levels are associated with an increased risk of AD [35], and chronic use of hydroxymethylglutaryl coenzyme A-reductase inhibitors (statins) has been reported to reduce the risk of developing AD by up to $75 \%$ [36]. In addition, robust scientific data indicate that hypercholesterolemia promotes $\mathrm{A} \beta$ production and deposition in a variety of animal models of $\mathrm{AD}$ and that cholesterol reduction strategies reduce $A \beta$ deposition [37]. Another study indicates that statins inhibit $A \beta$ formation in vitro [38].

Although a phase II study of atorvastatin $80 \mathrm{mg} /$ day monotherapy in 63 patients with mild to moderate AD found that the treated group had no deterioration in scores on cognitive or functional assessment scales after 12 months of treatment [35], a larger phase III study $(\mathrm{n}=600)$ in patients also receiving donepezil was completed in 2007 and found no benefit to adjunctive use of atorvastatin [39]. A phase III trial $(n=400)$ of simvastatin monotherapy was also completed in 2007 , and the results were reported to be negative as well.

Despite these negative findings, the epidemiologic data suggesting a protective effect (as opposed to a treatment effect) of statins in AD [40] are sufficiently encouraging that simvastatin $80 \mathrm{mg} /$ day is now in a phase II trial prevention study. This study plans to enroll 100 adults (35 to 69 years old) who have a parent with AD but who do not themselves exhibit any cognitive deficits. The primary outcome measures are CSF A $\beta$, inflammatory markers, and cholesterol as well as cognitive performance over time (Evaluating Simvastatin's Potential Role In Therapy (ESPRIT) [32].

\section{Insulin sensitizer: rosiglitazone}

Insulin signaling is known to have a role in memory function and may also influence the regulation of APP and $A \beta$ [41]. In addition, insulin-degrading enzyme is one of the enzymes active in clearance of $A \beta$ [42]. For 
these reasons, insulin abnormalities are of interest as causes of or contributors to cognitive impairment, and insulin resistance has been proposed as a potential target for $\mathrm{AD}$ prevention. Rosiglitazone acts as an insulin sensitizer, binding to receptors in fat cells that render the cells more responsive to insulin [43]. In the phase II trial ( $\mathrm{n}=511$ ), no difference between the rosiglitazone and placebo groups was found in the population as a whole, but an interaction between $A p o E$ \&4 genotype and outcome was identified in those on the highest dose of drug [44]. Specifically, non- $\varepsilon 4$ carriers were found to improve on rosiglitazone $8 \mathrm{mg}$. No serious safety concerns were noted. In the phase III trials, patients were stratified by $A p o E \& 4$ status. Regardless of whether rosiglitazone was used as monotherapy or adjunctive therapy, efficacy for mild to moderate $\mathrm{AD}$ was not demonstrated by either the ADAS-Cog or the CIBICplus. In meta-analyses unrelated to $\mathrm{AD}$ trials, cardiovascular morbidity with rosiglitazone was identified [45]. This safety concern will likely limit the scope of investigation for rosiglitazone for AD.

\section{Glycosaminoglycan mimetic: tramiprosate}

Structurally, tramiprosate is a glycosaminoglycan (GAG) mimetic designed to interfere with the actions of $A \beta$ early in the cascade of amyloidogenesis [46]. Tramiprosate is a modification of the amino acid taurine. It binds preferentially to soluble $A \beta$ peptide and maintains $A \beta$ in a nonfibrillar form, thereby inhibiting amyloid formation and deposition. Tramiprosate also interferes with $\beta$-sheet formation of amyloid.

In the phase II clinical trial, subjects randomly assigned to tramiprosate demonstrated sustained safety and tolerability as well as a reduction in CSF A 342 levels [47]. Additionally, the treated subjects remained near baseline as measured by ADAS-Cog after 20 months of treatment.

The phase III trial, which was conducted in 67 centers throughout North America, randomly assigned 1,052 patients with mild to moderate $\mathrm{AD}$ to tramiprosate 100 and $150 \mathrm{mg}$ twice daily or placebo [48]. Continued use of approved $\mathrm{AD}$ medications was allowed. The primary endpoints were the ADAS-Cog score, the Clinical Dementia Rating Scale-Sum of Boxes score, and change in hippocampal volume on magnetic resonance imaging. Tramiprosate was not significantly more effective than placebo on any of these outcome measures. In November 2007, the sponsor announced its intention to discontinue development of tramiprosate as a pharmaceutical and halted the European phase III trial. Again, a confounder of the phase III trial was an unusually strong placebo response [48]. In addition, there is some evidence that tramiprosate acts to promote the aggregation of tau protein [46]. Since 2008, tramiprosate has been marketed as the over-the-counter nutraceutical Vivimind.

\section{Chelating agents: clioquinol (PBT1)}

Proponents of chelation therapy have focused on identifying and extracting metallic ions co-localized to plaques. Clioquinol, an anti-malarial drug no longer used (because of toxicity to peripheral and optic nerves), has been shown to inhibit zinc and copper ions from binding to $A \beta$, thus promoting the solubilization and clearance of A $\beta$. A pilot phase II clinical trial was conducted in 36 subjects with moderate AD. The effect of treatment was significant in the more severely affected group (baseline ADAS-Cog score of at least 25) but the effect was attributed to substantial worsening of scores in those taking placebo in comparison with minimal deterioration for the clioquinol group. Plasma A $\beta 42$ levels declined in the clioquinol group and increased in the placebo group. Plasma zinc levels rose in the clioquinol-treated group. The drug was well tolerated. These data suggest that clioquinol improved cognition and lowered plasma levels of A $\beta 42$ in some patients. However, a phase III study was never undertaken and clioquinol is no longer in development for the treatment of AD [49].

\section{Conclusions}

In general, review of failed drug trials in $\mathrm{AD}$ can be productive if pitfalls that can be avoided in future trials are identified. Several general findings are worth noting. Except for the early vaccine trials and rosiglitazone, the major obstacle facing drug development over the last decade appears to be lack of demonstrated efficacy rather than safety. The logical possibilities to explain inefficacy are that the drugs developed thus far are simply ineffective in humans, that the amyloid hypothesis is not the right model, that the drugs are administered incorrectly (wrong dose, route, or disease stage), or that the drugs are working but the clinical trial complex is unable to detect the signal.

\section{The drugs are not effective in humans}

The possibility does exist that, at least for some of the drugs trialed, preclinical data are misleading. In vitro models may be too simplistic, lacking the complex interactions of pharmacokinetics and pharmacodynamics with physiology. Transgenic mouse models do not provide a true representation of $\mathrm{AD}$, as noted earlier. Many of the models lack pathological characteristics such as tangles, or plaque morphology and dissolution characteristics are different from those of human AD plaque. Thus, some drugs shown to work in vitro and in vivo may never be efficacious in humans. Alternatively, since animal studies are not a true reflection of the disease process in AD in humans, the disease in humans may be too advanced or too widespread at the symptomatic phase to be amenable to meaningful clinical effect. 


\section{The amyloid hypothesis is not the right model}

It would be difficult at this point to argue that the amyloid hypothesis does not describe at least some component of the pathogenetic pathway of AD. Amyloid immunotherapies have become a common approach to targeting the disease, but the results to date have not been consistently positive nor does targeting amyloid pathology change the outcome [6]. This does not rule out the possibility, however, that tau or other pathologies (or both) should also be targeted.

\section{The drugs are administered incorrectly}

Clinical trialists working in phase II and III studies have to trust that adequate time and attention have been paid in earlier phases of drug development to the identification of the appropriate drug dose. For the most part, this has not proven problematic. More important to drug success is the observation, already stated, that the $\mathrm{AD}$ mouse model more closely parallels preclinical $\mathrm{AD}$, so for drugs developed along this pathway, the focus of investigation should be on asymptomatic at-risk individuals or those with very early MCI. For the latter group, it would be important to avoid using the MMSE as a screening tool for subject inclusion/exclusion. In part because of ceiling effects and in part because of practice effects with the MMSE, potential subjects are often excluded by this measure even though it is clear that they are impaired from baseline. A more sensitive screening instrument such as the Montreal Cognitive Assessment could be used in place of the MMSE [50].

\section{The drugs work but clinical trials are not detecting efficacy}

Of the available explanations for failed trials, this appears to be the most likely candidate. Even a cursory look at clinical trial conduct reveals a number of potential problems, many of which are amenable to correction. One of the most significant problems from the standpoint of the clinical trialist is the heavy reliance on rating scales as outcome measures [3]. Regardless of the quality of rater training, any degree of subjectivity in assessment will introduce variance across sites and over time. Even for ostensibly 'objective' instruments such as the ADASCog, which is the most widely used measure of cognitive change in AD trials, variations in forms, administration procedures, and scoring rules exist [51]. More widespread use of human amyloid imaging is a critical next step in the improvement of outcome measures for AD trials.

The fact that so many of the AD drug trials failed in moving from phase II to phase III provides a clue as to other problems plaguing drugs under investigation. One factor that changes between these two phases is that the study population becomes more heterogeneous, and with this change comes the possibility that as-yet-unidentified confounding medical problems and medications will be introduced. As trials get larger, are 'less eligible' subjects enrolled? In addition, the group of trialists and research centers expands in moving to phase III, reaching out beyond the inner circle of investigators and coordinators. At least in some trials, the added personnel are relatively lacking in experience with the drug, not having been involved in phase I or II activities.

Another issue relates to the short duration of many clinical trials. Long trials are very difficult to conduct in elderly patients with a progressive disease like $\mathrm{AD}$, particularly since it also so profoundly affects caregivers, who usually serve as study partners. In addition, new drug development is big business, and the push to obtain data in support of a new drug application is a fact of life for the pharmaceutical industry. Those who conduct clinical trials are sometimes left to wonder whether an extension might turn a negative trial into a positive one.

Unexpected and large improvements in placebo populations have plagued several of the trials for $\mathrm{AD}$. This improvement is actually understandable from the point of view of the clinical trialist. Individuals enrolled in $\mathrm{AD}$ trials are seen on a regular basis by caring individuals who have a good understanding of how to talk to patients with dementia and how to deal with problematic behaviors. Whether specific non-trialrelated interventions are undertaken or not, positive interactions at these visits are bound to have beneficial effects. This is a difficult area to remedy without offense, but some thought should be given to ways in which the patient contacts could be 'sterilized' to help neutralize this effect. In addition, it could be expected that, given enough time, the placebo group would naturally decline. Perhaps a rule of thumb could be stated as follows: if your placebo group does not decline, your trial is too short.

This article is part of a review series on Failed clinical trials.

Other articles in the series can be found online at

http://alzres.com/series/failedtrials

\section{Abbreviations}

5-HT , serotonin $1 A ; A B$, amyloid-beta; $A D$, Alzheimer's disease; ADAS-ADL, Alzheimer's Disease Assessment Scale activities of daily living; ADAS-Cog, Alzheimer's Disease Assessment Scale cognitive subscale; APP, amyloid beta (A4) precursor protein; $\mathrm{Cl}$, confidence interval; $\mathrm{CIBIC}$, Clinician's Interview-

Based Impression of Change; CNS, central nervous system; CSF, cerebrospinal fluid; $\mathrm{GABA}_{\mathrm{R}^{\prime}}$ gamma-aminobutyric acid type $\mathrm{B}$; $\mathrm{HR}$, hazard ratio; HRT, hormone replacement therapy; $\mathrm{LH}$, luteinizing hormone; $\mathrm{MCl}$, mild cognitive impairment; MMSE, Mini-Mental State Examination; nAChR, nicotinic acetylcholine receptor; NMDA, N-methyl D-aspartate; WHIMS, Women's Health Initiative Memory Study.

\section{Competing interests}

SAJ and MNS declare that they have no competing interests but that they serve as investigators on several studies, including studies for Medivation (San Francisco, CA, USA), Eli Lilly and Company (Indianapolis, IN, USA), BristolMyers Squibb Company (Princeton, NJ, USA), Baxter (Deerfield, IL, USA), Avid Radiopharmaceuticals (Philadelphia, PA, USA ), GE Healthcare (Little Chalfont, Buckinghamshire, UK), Bayer (Leverkusen, Germany), Janssen-Cilag GmbH 
(Neuss, Germany), and Elan (Dublin, Ireland). MNS serves as an advisor/ consultant to AmeriSciences (Houston, TX, USA), Pfizer Inc (New York, NY, USA), Eisai (Woodcliff Lake, NJ, USA), GlaxoSmithKline (Uxbridge, Middlesex, UK), and Janssen-Cilag $\mathrm{GmbH}$.

\section{Author contributions}

SAJ and MNS contributed equally to the drafting of this review. Both authors read and approved the final manuscript.

\section{Acknowledgments}

The authors thank Barbara Voepel for her assistance in arranging and formatting the references. This review was supported by NIA P30 AG 019610 and BSHRI.

\section{Published: 15 April 2011}

\section{References}

1. Hardy J, Selkoe DJ: The amyloid hypothesis of Alzheimer's disease: progress and problems on the road to therapeutics. Science 2002, 297:353-356.

2. Zahs KR, Ashe KH: 'Too much good news' - are Alzheimer mouse models trying to tell us how to prevent, not cure, Alzheimer's disease? Trends Neurosci 2010, 33:381-389.

3. Becker RE, Greig NH: Alzheimer's disease drug development: old problems require new priorities. CNS Neurol Disord Drug Targets 2008, 7:499-511.

4. Lemere CA: Developing novel immunogens for a safe and effective Alzheimer's disease vaccine. Prog Brain Res 2009, 175:83-93.

5. Vellas B, Black R, Thal LJ, Fox NC, Daniels M, McLennan G, Tompkins C, Leibman C, Pomfret M, Grundman M: Long-term follow-up of patients immunized with AN1792: reduced functional decline in antibody responders. Curr Alzheimer Res 2009, 6:144-151.

6. Holmes C, Boche D, Wilkinson D, Yadegarfar G, Hopkins V, Bayer A, Jones RW, Bullock R, Love S, Neal JW, Zotova E, Nicoll JA. Long-term effects of Abeta42 immunisation in Alzheimer's disease: follow-up of a randomised, placebocontrolled phase I trial. Lancet 2008, 372:216-223.

7. Greig NH, De Micheli E, Holloway HW, Yu QS, Utsuki T, Perry TA, Brossi A, Ingram DK, Deutsch J, Lahiri DK, Soncrant TT: The experimental Alzheimer drug phenserine: preclinical pharmacokinetics and pharmacodynamics. Acta Neurol Scand Suppl 2000, 176:74-84.

8. Greig NH, Sambamurti K, Yu QS, Brossi A, Bruinsma GB, Lahiri DK: An overview of phenserine tartrate, a novel acetylcholinesterase inhibitor for the treatment of Alzheimer's disease. Curr Alzheimer Res 2005, 2:281-290.

9. Kadir A, Andreasen N, Almkvist O, Wall A, Forsberg A, Engler H, Hagman G, Lärksäter M, Winblad B, Zetterberg H, Blennow K, Långström B, Nordberg A: Effect of phenserine treatment on brain functional activity and amyloid in Alzheimer's disease. Ann Neurol 2008, 63:621-631.

10. Alzforum News: Investigational Drug Phenserine Fails [www.alzforum.org/ new/detail.asp?id=1257].

11. Dunbar G, Demazieres A, Monreal A, Cisterni C, Metzger D, Kuchibhatla R, Luthringer R: Pharmacokinetics and safety profile of ispronicline (TC-1734), a new brain nicotinic receptor partial agonist, in young healthy male volunteers. J Clin Pharmacol 2006, 46:715-726.

12. Alzforum: Drugs in Clinical Trials - AZD3480 [www.alzforum.org/drg/drc/ detail.asp?id=117]

13. Yan FL, Zheng Y, Zhao FD: Effects of Ginkgo biloba extract EGb761 on expression of RAGE and LRP-1 in cerebral microvascular endothelial cells under chronic hypoxia and hypoglycemia. Acta Neuropathol 2008, 116:529-535.

14. Snitz BE, O'Meara ES, Carlson MC, Arnold AM, Ives DG, Rapp SR, Saxton J, Lopez OL, Dunn LO, Sink KM, DeKosky ST: Ginkgo biloba for preventing cognitive decline in older adults: a randomized trial. JAMA 2009, 302:2663-2670.

15. DeKosky ST, Williamson JD, Fitzpatrick AL, Kronmal RA, Ives DG, Saxton JA Lopez OL, Burke G, Carlson MC, Fried LP, Kuller LH, Robbins JA, Tracy RP, Woolard NF, Dunn L, Snitz BE, Nahin RL, Furberg CD; Ginkgo Evaluation of Memory (GEM) Study Investigators: Ginkgo biloba for prevention of dementia: a randomized controlled trial. JAMA 2008, 300:2253-2262.

16. Birks J, Grimley Evans J: Ginkgo biloba for cognitive impairment and dementia. Cochrane Database Syst Rev 2009, (1):CD003120.

17. Weinmann S, Roll S, Schwarzbach C, Vauth C, Willich SN. Effects of Ginkgo biloba in dementia: systematic review and meta-analysis. BMC Geriatr 2010, $10: 14$
18. Rammes G, Schierloh A: Neramexane (merz pharmaceuticals/forest laboratories). IDrugs 2006, 9:128-135.

19. Froestl W, Gallagher M, Jenkins H, Madrid A, Melcher T, Teichman S, Mondadori CG, Pearlman R: SGS742: the first GABA(B) receptor antagonist in clinical trials. Biochem Pharmacol 2004, 68:1479-1487.

20. Pike CJ: Estrogen modulates neuronal BCl-xL expression and beta-amyloidinduced apoptosis: relevance to Alzheimer's disease. J Neurochem 1999 72:1552-1563

21. Xu H, Gouras GK, Greenfield JP, Vincent B, Naslund J, Mazzarelli L, Fried G, Jovanovic JN, Seeger M, Relkin NR, Liao F, Checler F, Buxbaum JD, Chait BT, Thinakaran G, Sisodia SS, Wang R, Greengard P, Gandy S: Estrogen reduces neuronal generation of Alzheimer beta-amyloid peptides. Nat Med 1998, 4:447-451.

22. Yaffe K, Sawaya G, Lieberburg I, Grady D: Estrogen therapy in postmenopausal women: effects on cognitive function and dementia. JAMA 1998, 279:688-695.

23. Hogervorst E, Yaffe K, Richards M, Huppert F: Hormone replacement therapy for cognitive function in postmenopausal women. Cochrane Database Syst Rev 2002, (3):CD003122.

24. Hogervorst E, Williams J, Budge M, Riedel W, Jolles J: The nature of the effect of female gonadal hormone replacement therapy on cognitive function in post-menopausal women: a meta-analysis. Neuroscience 2000, 101:485-512.

25. Shumaker SA, Legault C, Rapp SR, Thal L, Wallace RB, Ockene JK, Hendrix SL, Jones BN 3rd, Assaf AR, Jackson RD, Kotchen JM, Wassertheil-Smoller S Wactawski-Wende J; WHIMS Investigators: Estrogen plus progestin and the incidence of dementia and mild cognitive impairment in postmenopausal women: the Women's Health Initiative Memory Study: a randomized controlled trial. JAMA 2003, 289:2651-2662

26. Espeland MA, Rapp SR, Shumaker SA, Brunner R, Manson JE, Sherwin BB, Hsia J, Margolis KL, Hogan PE, Wallace R, Dailey M, Freeman R, Hays J; Women's Health Initiative Memory Study: Conjugated equine estrogens and global cognitive function in postmenopausal women: Women's Health Initiative Memory Study. JAMA 2004, 291:2959-2968.

27. Casadesus G, Garrett MR, Webber KM, Hartzler AW, Atwood CS, Perry G, Bowen RL, Smith MA: The estrogen myth: potential use of gonadotropinreleasing hormone agonists for the treatment of Alzheimer's disease. Drugs R D 2006, 7:187-193.

28. Casadesus G, Webber KM, Atwood CS, Pappolla MA, Perry G, Bowen RL, Smith MA: Luteinizing hormone modulates cognition and amyloid-beta deposition in Alzheimer APP transgenic mice. Biochim Biophys Acta 2006 1762:447-452

29. Bowen RL, Smith MA, Harris PL, Kubat Z, Martins RN, Castellani RJ, Perry G, Atwood CS: Elevated luteinizing hormone expression colocalizes with neurons vulnerable to Alzheimer's disease pathology. J Neurosci Res 2002 70:514-518.

30. Smith MA, Perry G, Atwood CS, Bowen RL: Estrogen replacement and risk of Alzheimer disease. JAMA 2003, 289:1100; author reply 1101-1102.

31. Schechter LE, Dawson LA, Harder JA: The potential utility of 5-HT1A receptor antagonists in the treatment of cognitive dysfunction associated with Alzheimer's disease. Curr Pharm Des 2002, 8:139-145.

32. ClinicalTrials.gov homepage [www.clinicaltrials.gov].

33. Wilcock GK, Black SE, Hendrix SB, Zavitz KH, Swabb EA, Laughlin MA: Efficacy and safety of tarenflurbil in mild to moderate Alzheimer's disease: a randomised phase II trial. Lancet Neurol 2008, 7:483-493.

34. Sabbagh MN: Drug development for Alzheimer's disease: where are we now and where are we headed? Am J Geriatr Pharmacother 2009, 7:167-185.

35. Sparks DL, Sabbagh MN, Connor DJ, Lopez J, Launer L, Browne P, Wasser D, Johnson-Traver S, Lochhead J, Ziolwolski C: Atorvastatin for the treatment of mild to moderate Alzheimer disease: preliminary results. Arch Neuro/ 2005 62:753-757.

36. Wolozin B, Kellman W, Ruosseau P, Celesia GG, Siegel G: Decreased prevalence of Alzheimer disease associated with 3-hydroxy-3methyglutaryl coenzyme A reductase inhibitors. Arch Neurol 2000, 57:1439-1443.

37. Sparks DL: The early and ongoing experience with the cholesterol-fed rabbit as a model of Alzheimer's disease: the old, the new and the pilot. J Alzheimers Dis 2008, 15:641-656.

38. Wang Q, Yan J, Chen X, Li J, Yang Y, Weng J, Deng C, Yenari MA: Statins: multiple neuroprotective mechanisms in neurodegenerative diseases. Exp Neurol 2010 Apr 18. [Epub ahead of print]

39. Feldman HH, Doody RS, Kivipelto M, Sparks DL, Waters DD, Jones RW, 
Schwam E, Schindler R, Hey-Hadavi J, DeMicco DA, Breazna A: Randomized controlled trial of atorvastatin in mild to moderate Alzheimer disease: LEADe. Neurology 2010, 74:956-964

40. Scott HD, Laake K: Statins for the prevention of Alzheimer's disease. Cochrane Database Syst Rev 2001, (4):CD003160

41. Craft S, Watson GS: Insulin and neurodegenerative disease: shared and specific mechanisms. Lancet Neurol 2004, 3:169-178.

42. Wang DS, Dickson DW, Malter JS: beta-Amyloid degradation and Alzheimer's disease. J Biomed Biotechnol 2006, 2006:58406.

43. Gurnell M: Peroxisome proliferator-activated receptor gamma and the regulation of adipocyte function: lessons from human genetic studies. Best Pract Res Clin Endocrinol Metab 2005, 19:501-523.

44. Risner ME, Saunders AM, Altman JF, Ormandy GC, Craft S, Foley IM, ZvartauHind ME, Hosford DA, Roses AD: Efficacy of rosiglitazone in a genetically defined population with mild-to-moderate Alzheimer's disease. Pharmacogenomics J 2006, 6:246-254.

45. Nissen SE, Wolski K: Rosiglitazone revisited: an updated meta-analysis of risk for myocardial infarction and cardiovascular mortality. Arch Intern Med 2010 Jun 28. [Epub ahead of print].

46. Santa-Maria I, Hernandez F, Del Rio J, Moreno FJ, Avila J: Tramiprosate, a drug of potential interest for the treatment of Alzheimer's disease, promotes an abnormal aggregation of tau. Mol Neurodegener 2007, 2:17.

47. Aisen PS, Gauthier S, Vellas B, Briand R, Saumier D, Laurin J, Garceau D: Alzhemed: a potential treatment for Alzheimer's disease. Curr Alzheimer Res 2007, 4:473-478
48. Gauthier S, Aisen PS, Ferris SH, Saumier D, Duong A, Haine D, Garceau D, Suhy J, Oh J, Lau W, Sampalis J: Effect of tramiprosate in patients with mild-tomoderate Alzheimer's disease: exploratory analyses of the MRI sub-group of the Alphase study. J Nutr Health Aging 2009, 13:550-557.

49. Ritchie CW, Bush Al, Mackinnon A, Macfarlane S, Mastwyk M, MacGregor L, Kiers L, Cherny R, Li QX, Tammer A, Carrington D, Mavros C, Volitakis I, Xilinas M, Ames D, Davis S, Beyreuther K, Tanzi RE, Masters CL: Metal-protein attenuation with iodochlorhydroxyquin (clioquinol) targeting Abeta amyloid deposition and toxicity in Alzheimer disease: a pilot phase 2 clinical trial. Arch Neurol 2003, 60:1685-1691.

50. Nasreddine ZS, Phillips NA, Bedirian V, Charbonneau S, Whitehead V, Collin I, Cummings JL, Chertkow H: The Montreal Cognitive Assessment, MoCA: a brief screening tool for mild cognitive impairment. J Am Geriatr Soc 2005, 53:695-699.

51. Connor DJ, Sabbagh MN: Administration and scoring variance on the ADAS-Cog. J Alzheimers Dis 2008, 15:461-464.

doi:10.1186/alzrt73

Cite this article as: Jacobson SA, Sabbagh MN: Investigational drugs for the treatment of AD: what can we learn from negative trials? Alzheimer's Research \& Therapy 2011, 3:14 